\title{
UMTS rapid response real-time seismic networks: implementation and strategies at INGV
}

\author{
A. Govoni, L. Margheriti, M. Moretti, V. Lauciani, G. Sensale, A. Bucci, and F. Criscuoli \\ Istituto Nazionale di Geofisica e Vulcanolgia, Via di Vigna Murata, 605, Rome, Italy \\ Correspondence to: A. Govoni (aladino.govoni@ingv.it)
}

Received: 13 August 2015 - Revised: 21 October 2015 - Accepted: 27 October 2015 - Published: 16 December 2015

\begin{abstract}
Universal Mobile Telecommunications System (UMTS) and its evolutions are nowadays the most affordable and widespread data communication infrastructure available almost world wide. Moreover the always growing cellular phone market is pushing the development of new devices with higher performances and lower power consumption. All these characteristics make UMTS really useful for the implementation of an "easy to deploy" temporary real-time seismic station. Despite these remarkable features, there are many drawbacks that must be properly taken in account to effectively transmit the seismic data: Internet security, signal and service availability, power consumption.
\end{abstract}

- Internet security: exposing seismological data services and seismic stations to the Internet is dangerous, attack prone and can lead to downtimes in the services, so we setup a dedicated Virtual Private Network (VPN) service to protect all the connected devices.

- Signal and service availability: while for temporary experiment a carefull planning and an accurate site selection can minimize the problem, this is not always the case with rapid response networks. Moreover, as with any other leased line, the availability of the UMTS service during a seismic crisis is basically unpredictable. Nowadays in Italy during a major national emergency a Committee of the Italian Civil Defense ensures unified management and coordination of emergency activities. Inside it the telecom companies are committed to give support to the crisis management improving the standards in their communication networks.

- Power consumption: it is at least of the order of that of the seismic station and, being related to data flow and signal quality is largely unpredictable. While the most secure option consists in adding a second independent solar power supply to the seismic station, this is not always a very convenient solution since it doubles the cost and doubles the equipment on site. We found that an acceptable trade-off is to add an inexpensive Low Voltage Disconnect (LVD) circuit to the UMTS router power supply that switches off the data transmission when the power is low. This greatly reduces the probability of data loss but lowers the real-time data availabilty. This approach guarantees on the average a satisfactory data acquistion rate, only in very few cases and when the real-time data is extremely important for a particular site we needed to double the power supply on the site.

Overall the UMTS data transmission has been used in most temporary seismic experiments and in all seismic emergencies happened in Italy since 2010 and has proved to be a very cost effective approach with real-time data acquisition rates usually greater than $97 \%$ and all the benefits that result from the fast integration of the temporary data in the National Network monitoring system and in the EIDA data bank.

\section{Introduction}

The benefits of portable real-time seismic networks are several and well known. During the management of a temporary experiment from the real-time data flow is possible to detect and fix quickly problems with power supply, time synchronization, disk failures and, most important, seismic signal quality degradation due to unexpected noise sources or sensor alignment/tampering. This usually minimizes the field maintenance trips and maximizes both the quantity and the quality of the acquired data. When the area of the temporary experiment is not well monitored by the local permanent net- 
work, the real-time data from the temporary experiment can be fed to the permanent network monitoring system improving greatly both the real-time hypocentral locations and the final revised bulletin.

All these benefits apply also in case of seismic crises when the rapid deployment stations can significantly contribute to the aftershock analysis.

Nowadays data transmission using meshed radio networks or satellite systems is not a big technological problem for a permanent seismic network where each site is optimized for the device power consumption and is usually installed by properly specialized technicians that can configure transmission devices and align antennas. This is not usually practical for temporary networks and especially for rapid response networks where the installation time is the main concern.

These difficulties are substantially lowered using the now widespread UMTS technology for data transmission. A small (but sometimes power hungry) properly configured device with an omnidirectional antenna must be added to the station assembly. All setups are usually configured before deployment and this allows for an easy installation also by untrained personnel.

Anyway, there are many drawbacks that must be properly taken in account to effectively transmit the seismic data: Internet security, signal and service availability, power consumption.

Once you access the Internet through a UMTS router your are totally exposed, so you have to be sure that all service ports used are strong enough to withstand possible attacks. We solved this aspect setting up a dedicated Virtual Private Network (VPN) service for all the connected devices, so no data acquisition service port is exposed to the Internet and all the devices seem to belong to a local network.

The signal and service availability are not always known a priori. The telecommunication companies tend to follow the population density when planning the signal coverage of an area, while the best sites for seismic stations are usually far from cultural noise. As for any other public line, the availability of the UMTS service during a seismic crisis is basically unpredictable.

The power consumption of UMTS routers is still usually higher than that of the seismic station and strongly depends from the level of the signal in the site. When the seismic station is solar powered, the power system must at least be doubled in capacity. In some cases, like mountain sites during winter, a completely independent power supply for the UMTS router is advisable to minimize data loss due to power outage in case of long periods of bad weather.

The experimentation of the first UMTS devices began at Istituto Nazionale di Geofisica e Vulcanologia (INGV) in 2009 and the first test installation was performed just after the L'Aquila seismic sequence. Since then UMTS real-time stations have been deployed in several temporary experiments and in almost all seismic sequences (see Fig. 1) with increasingly satisfactory results. Table 1 lists all the relevant details of the temporary experiments using real-time stations, more details are reported in (Moretti et al., 2016).

Once addressed the main problems outlined above, the managment of such real-time networks proves to be extremely cost effective minimizing on one side the cost of periodical maintenace field trips and maximizing the data availability both for real-time monitoring and for standard research. Maintenance field trips are needed only to collect periodically the local copy of the data and to fix eventual hardware problems timely as they happen. Moreover most of the times the additional real-time sites prove to be very useful to the National Network monitoring system increasing both the detectivity and the hypocentral location quality.

\section{A UMTS OpenVPN based real-time data acquisition scheme}

UMTS is not very different from a home DSL connection, so the most difficult thing to do is really to reach a client behind a provider. Most provider's firewalls shield connections not initiated by the client (i.e. the seismic station), "strange" port/protocols (like seedlink 18000) and will usually change frequently the connection IP address.

This situation is not really the best for seedlink systems in which is the data server that looks for the client data, when the data link is initiated by the station (like RefTek 130) there are usually no big problems. You just "plug and acquire".

To overcome these problems you must use a UMTS router (not a simple modem) that can face more complex network situations and can do several tricks if needed.

A very "quick\&dirty" approach is to use a UMTS router with DynDNS support, a m2m (machine to machine) UMTS contract with a local provider and a DynDNS subscription (there are also open-source/free solutions). This gives to the remote station a valid Internet address (something like mystation.dynadns.org) that is resolved to the router current IP address and updated at any change. The router NAT can be configured to forward the connections to the data service port directly to the seismic data logger behind the router.

This is basically all, but this setup is somewhat unreliable and insecure: all used ports are exposed to the Internet and the address lookups and the DynDNS updates usually contribute to the overall latency of the station.

A much better solution consists in setting up a Virtual Private Network (VPN) supported by the UMTS router (basically all devices have at least one and any VPN type is good enough for seismological services - we choose OpenVPN). Any UMTS subscription is fine in this case.

The benefit is that all the stations now belong to a private network that you directly manage. All real world problems (re-connections, IP changes, firewalls, etc.) are handled automatically by the VPN server and there are no service ports exposed except of course the VPN one (that is usually strong enough). 
Table 1. List and details of all INGV temporary experiment and emergency networks deploying real-time seismic stations since 2009.

\begin{tabular}{|c|c|c|c|c|}
\hline $\begin{array}{l}\text { Emergency/ } \\
\text { Experiment }\end{array}$ & Date & $\begin{array}{l}\text { Number of } \\
\text { UMTS stations }\end{array}$ & Codes & Reference \\
\hline Em. Frusinate (Lazio) & Oct 2009-Jan 2010 & $3 / 4$ & $\begin{array}{l}\text { T0202 } \\
\text { T0203 } \\
\text { T0205 }\end{array}$ & Moretti et al. (2011b) \\
\hline Em. Fermano (Marche) & Jan 2010-Mar 2010 & $2 / 2$ & $\begin{array}{l}\text { T0401 } \\
\text { T0402 }\end{array}$ & Govoni et al. (2012) \\
\hline Em. Montefeltro (Romagna) & May 2011-Sep 2011 & $2 / 4$ & $\begin{array}{l}\text { T0501 } \\
\text { T0502 }\end{array}$ & Moretti et al. (2011a) \\
\hline Em. Pollino (Calabria) & Nov 2011-Jun 2015 & $\begin{array}{l}3 / 5 \\
2 / 5\end{array}$ & $\begin{array}{l}\text { T0711 } \\
\text { T0712 } \\
\text { T0715 } \\
\text { T0716 } \\
\text { T0721 } \\
\text { T0724 }\end{array}$ & Margheriti et al. (2013) \\
\hline Em. Lunigiana (Toscana) & Jun 2013-Nov 2013 & $2 / 6$ & $\begin{array}{l}\text { T0911 } \\
\text { T0912 }\end{array}$ & Margheriti et al. (2014) \\
\hline Em. Matese (Molise) & Dec 2013-Mar 2014 & $2 / 2$ & $\begin{array}{l}\text { T1011 } \\
\text { T1012 }\end{array}$ & De Gori et al. (2014) \\
\hline Ex. ENI-Val D’Agri & Jan 2014-present & $2 / 2$ & $\begin{array}{l}\text { AG11 } \\
\text { AG51 }\end{array}$ & - \\
\hline Ex. EASI & Jul 2014-Aug 2015 & $3 / 4$ & $\begin{array}{l}\text { XT.AAE51 } \\
\text { XT.AAE53 } \\
\text { XT.AAE54 }\end{array}$ & Govoni et al. (2016) \\
\hline Ex. TOTAL & Jan 2014-present & $1 / 12$ & TT08 & - \\
\hline
\end{tabular}

This approach is much more secure and robust and you get an extra benefit in terms of bandwidth because the VPN tunnels are encrypted and compressed. The data acquisition scheme implemented at INGV is shown in Fig. 2. In this case the OpenVPN server has been installed directly on the data acquisition server. This system currently uses only the RefTek data loggers managed by the INGV Mobile Network but the same scheme can be used with any Ethernet capable data logger available on the market. When the UMTS router wakes up it will connect to the UMTS service provider and immediately after it will establish a VPN tunnel with the OpenVPN server. From this moment the remote RefTek station can connect to the RTPD data service and transmit data. All the data received by the RTPD is made available also to the SeedLink server using the standard plug-in. The other components of the National Network data acquisition system will access the real-time data via the SeedLink server. All devices, both seismic stations and routers can securely be accessed on the private LAN for checks and re-configuration purposes using their specific software tools. Moreover the whole proprietary data acquisition chain is totally abstracted behind the SeedLink server for a uniform data access. Sev- eral other vendor data acquisition chains can be implemented in parallel.

This system has been implemented and successfully managed for some years on a physical server and is now being ported to the new HA (High Availability) virtual machine cluster platform adopted by the INGV National Network for all data acquisition services.

\section{The hardware implementation}

We are currently using the Conel (http://www.conel.com) UR5 and UR5i v2 UMTS industrial routers (see Fig. 3). These devices have reasonable power consumption ranging from $2 \mathrm{~W}$ in continuous data transmission with good UMTS signal up to $5 \mathrm{~W}$ when the signal is poor and re-connections to the provider are frequent. These devices have all sort of nice features: $12 \mathrm{~V}$ power supply, an Ethernet 10/100 port, VPN support (IPSec, OpenVPN and L2TP), DHCP, NAT, NAT-T, DynDNS, NTP, VRRP. They have proved be rock solid in harsh conditions and they can also be remotely controlled using standard SMS messages. 


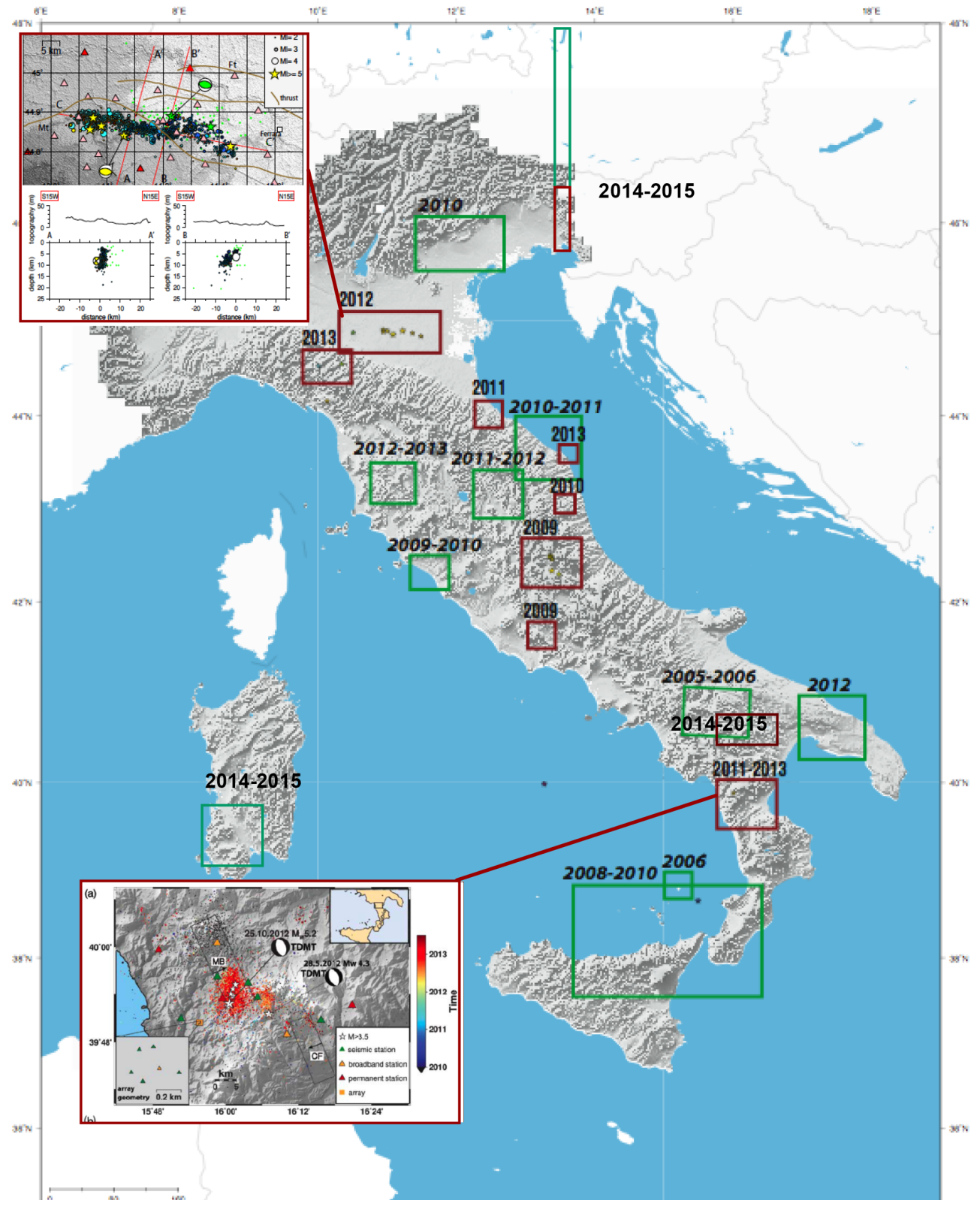

Figure 1. INGV temporary networks deployed in the last 10 years: the green rectangles represent experiment or emergency areas where only stand alone seismic stations were used, while the red rectangles are experiment or emergency areas where at least one real-time UMTS station was used.

The standard packaging is ruggerized inside a waterproof box with only two external connectors: one for the antenna (either omni or directional) and one for the POE Ethernet cable. The router box has a label with an ID and all the network parameters needed to configure the data-logger and also a $\mathrm{QR}$ code that let the operator access all site info using a smartphone.

An external switch-box takes power and Ethernet from the data logger connectors and provides a POE connection to the router. The Ethernet port on the switch-box can be used to connect to the router for maintenance.
This setup allows for maximum flexibility and modularity. Cabling and connections are studied to allow also untrained personnel to install easily the device and this is well suited for rapid deployment situations.

\section{The network managment}

The power consumption of UMTS routers is still usually higher than that of the seismic station and strongly depends on the level of the signal in the site. When the seismic station 


\section{REF TEK Real-Time VPN Architecture}

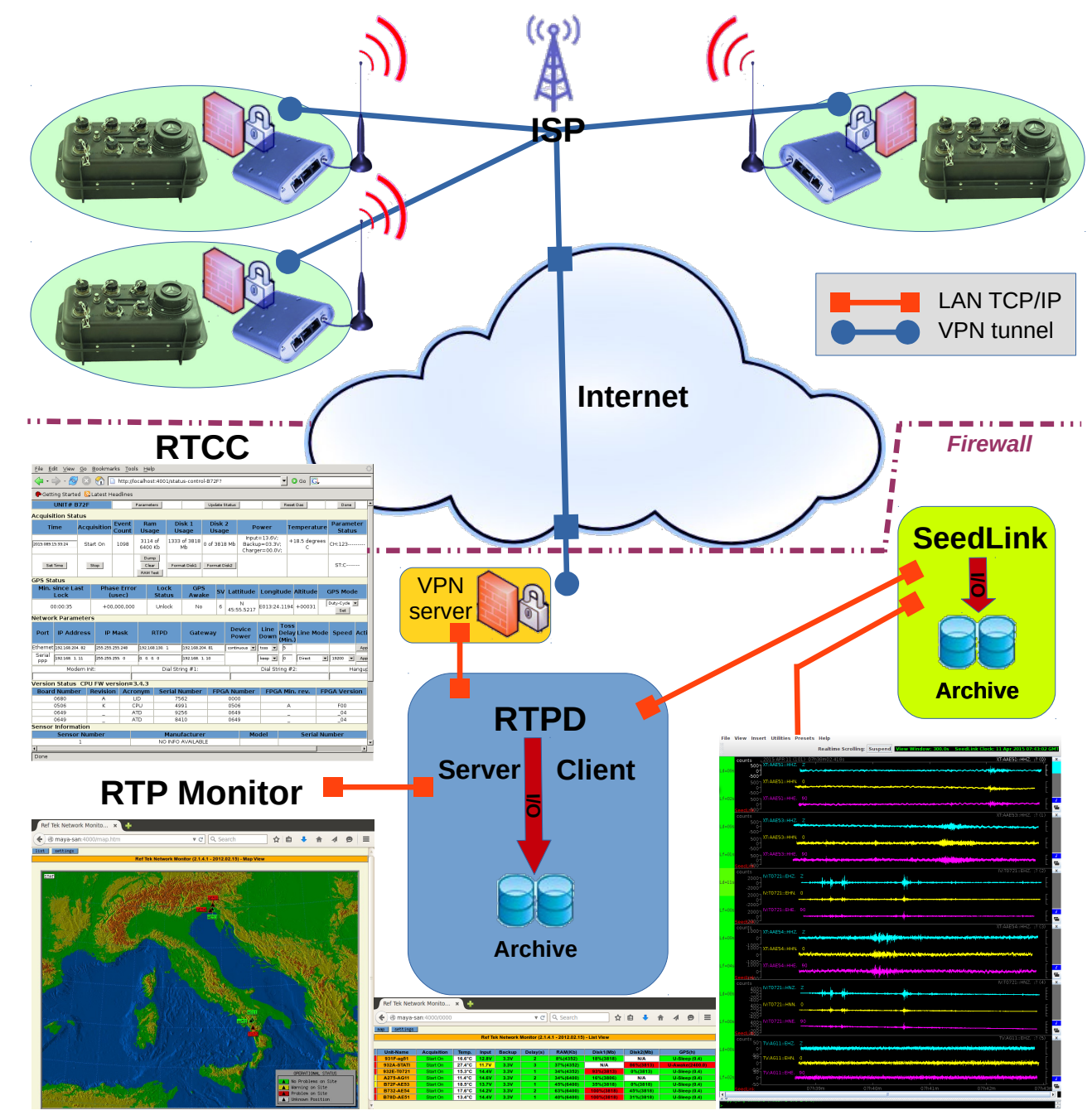

Figure 2. The UMTS OpenVPN based data acquisition scheme adopted for the RefTek data loggers managed by the INGV Mobile Network. When the UMTS router connects to the Internet it establish a VPN tunnel with the OpenVPN server installed on the data acquisition server. From this moment the remote data logger connects to the RTPD data service on a private LAN. All devices and the data acquisition process can be monitored and configured using specific tools. All the data acquired by the RTPD is made available to the SeedLink server. This scheme can be used with any Ethernet capable data logger available on the market.

is powered from the mains it is just a problem of correctly dimension the backup battery for the desired autonomy in case of temporary blackout. The router has several programmable $\mathrm{I} / \mathrm{O}$ and it is easy to setup a circuit that will raise one $\mathrm{I} / \mathrm{O}$ in case of mains failure and trigger a SMS message of alert.

When the seismic station is solar powered, the power system must at least be doubled in capacity. In line of principle to avoid data loss due to the real-time transmission a totally independent power system for the router only should be added. This is not always practical and is indeed expensive, but in some cases, like mountain sites with low signal during winter, is advisable.
While temporary experiment are usually fairly well planned in advance, a rapid deployment seismic station must be developed to face the worst case situation while being practical and fast to install. To avoid excessive weight and equipment volume for additional batteries and solar panels, we decided to find a reasonable tradeoff for the rapid deployment stations. When the station is deployed the battery is doubled and the router is equipped with a specific Low Voltage Disconnect (LVD) circuit that will switch off the power at a threshold of $12 \mathrm{~V}(0.5 \mathrm{~V}$ higher that the solar regulator). So when the power system is not enough for the station either for bad weather conditions or for fluctuations in the UMTS 

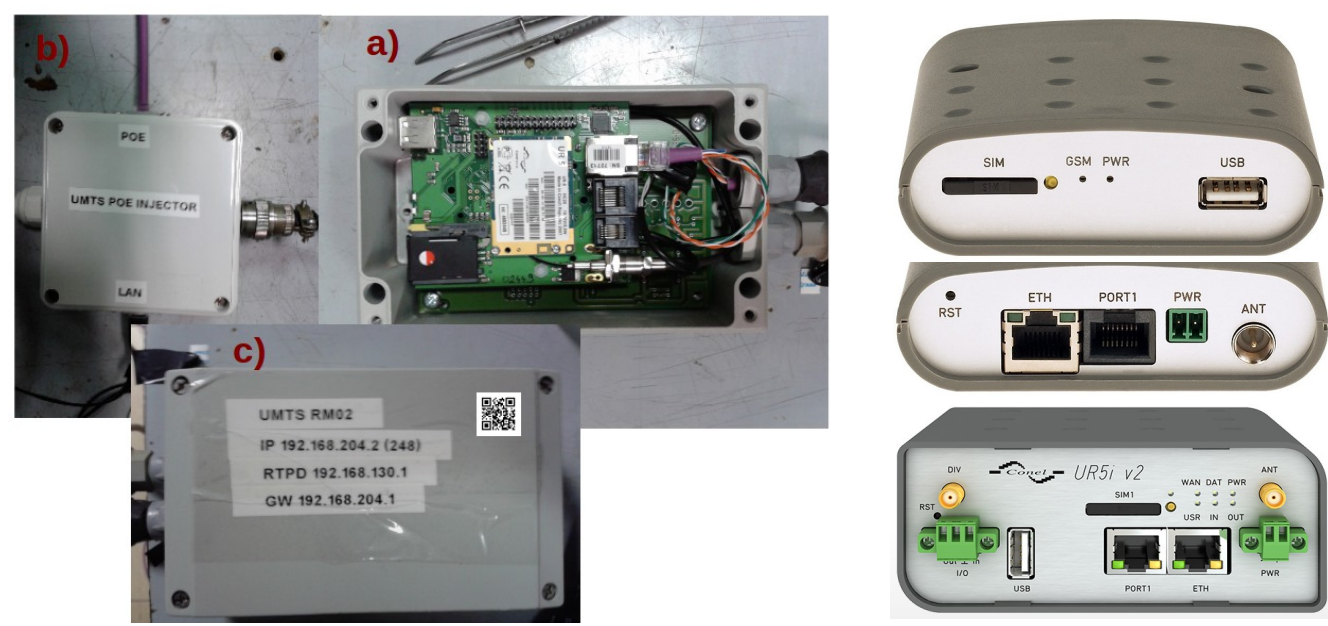

Figure 3. On the right the Conel UR5 (upper) and the Conel UR5i v2 UMTS routers used in this application. On the left the device packaged for installation on site; (a) the internal board is installed in a waterproof case and connect to a POE (Power over Ethernet) cable and to the antenna cable; (b) a switch-box takes power and Ethernet from the station and combines them in a POE connector; (c) the complete assembly of the router with a label providing all Ethernet configuration info for the RefTek station (RefTek 130 do not implement a DHCP client) and a $\mathrm{QR}$ code that allows the operator to access all station info.

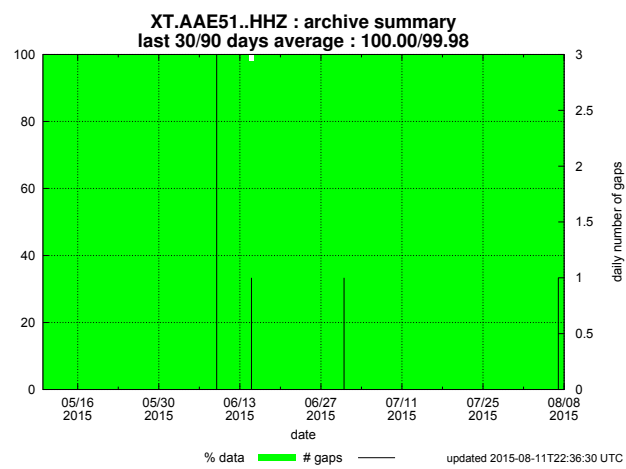

(a) XT.AAE51..HHZ

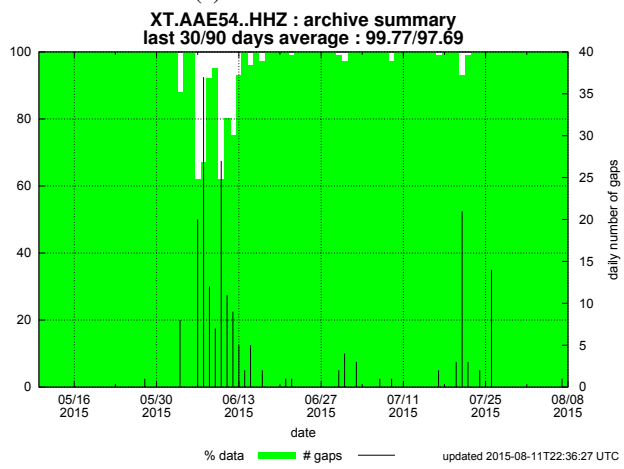

(c) XT.AAE54..HHZ

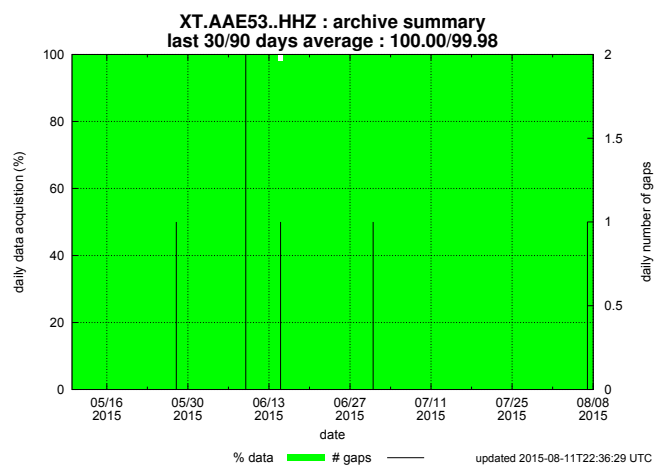

(b) XT.AAE53..HHZ

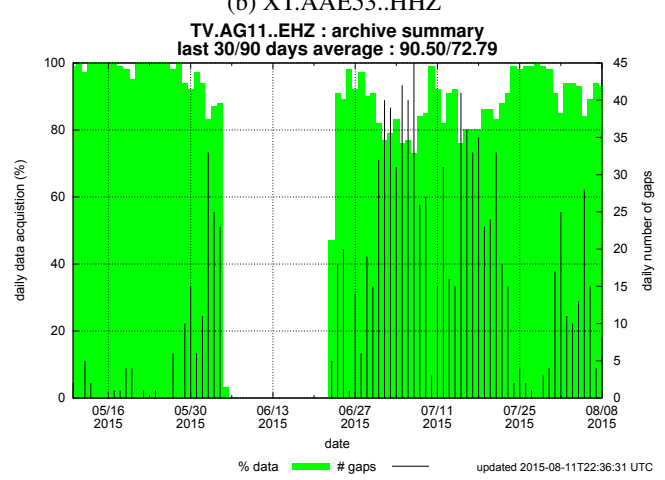

(d) TV.AG11..EHZ

Figure 4. The data acquistion status of some real-time UMTS stations currently installed. Green boxes represent the daily percentage of data present in the archive, while black impulses represent the number of gaps day ${ }^{-1}$ normally related to UMTS service problems. Panels (a) to (c) show results for three broad-band stations belonging to the EASI transect (Plomerova et al., 2015). They have been working remarkably well since August 2014 scoring an overall $99.97 \%$ of real-time data acquisition, only the XT.AAE54. (c) is showing some connection problem in the second week of Jun 2015 with peaks of 30-35 gaps in a day. The worst case is in (d). This station is sited in a rural area of the Val D'Agri (Southern Italy) with a very low signal level (less than $-100 \mathrm{~dB}$ ). After several days with $20-30$ gaps day ${ }^{-1}$, the UMTS router just stopped connecting. When the station was serviced and the router rebooted, data acquistion started again but with a very high number of daily gaps and an unsatisfactory average $90 \%$ daily data acquisition rate. 
signal only the router is switched off while the data acquisition continues locally. This lowers the probability of data loss due to power outage without increasing excessively the installation work. Monitoring remotely the station, adjustments to the power system can be planned at the next maintenance.

Figure 4 shows the data acquisition statistics of some of the stations currently acquired with this system. The first three panels are relative to broad-band stations installed in the EASI transect (Plomerova et al., 2015) since August 2014. All sites were well planned, XT.AAE51 and XT.AAE54 are mains powered with battery backup while XT.AAE53 has a solar power system. All sites have a very good UMTS signal and the stations have been operating with no particular data transmission issue scoring an overall $99.97 \%$ of data transmission. Only the XT.AAE54 has suffered from an unexpected fluctuations in the service around May 2015 with several gaps per day (peack $\sim 30$ 35 gaps day $^{-1}$ ).

The worst case is showed in panel (d). This station is sited in a rural area of the Val D'Agri (Southern Italy) with a very low signal level (less than $-100 \mathrm{dBi}$ ). After several days with 20-30 gaps day ${ }^{-1}$, the UMTS router just stopped connecting. When the station was serviced and the router rebooted, data acquisition started again but with a very high number of daily gaps and an unsatisfactory average $90 \%$ daily data acquisition rate.

\section{Conclusions}

We describe here the implementation of a UMTS based portable seismic network for both temporary experiments and rapid response applications developed at INGV.

The first field experimentation of this approach dates back to the 2009 L'Aquila aftershock sequence and since then it has been customized and refined to overcome most reliability and security issues using an industry standard VPN architecture that allows to avoid UMTS provider firewall problems and does not expose to the Internet the usually weak and attack prone data acquisition ports. With this approach all the devices are protected inside a local network and the only exposed port is the VPN server one. This solution improves both the security and the bandwidth available to data transmission.

While most of the experimentation has been carried out using the RefTek units of the INGV Mobile Network this solution applies equally well to most seismic data loggers available on the market.

This long experimentation has given positive results. With a somewhat moderate investment of time in setup, IT resources and money for UMTS routers there are several advantages in the managment of real-time temporary seismic networks and a sensible reduction in the operative costs respect to stand-alone deployment. Also the quality and the quantity of the data recorded is usually higher and there are also several benefits in all standard post processing activities that can be arranged to work in quasi real-time. A certain percentage of data loss must always be taken in account because UMTS, as any other public leased line, is not a high availability dedicated infrastructure. The quality and the availability of the service is indedd improving also during seismic emergency.

INGV is currently involved in the AlpArray project (AlpArray, 2015) that aims to study the greater Alpine area with high-quality broadband seismology experiments using $350+$ densely spaced temporary stations. In this very demanding experiment INGV will deploy all real-time stations with the main motivation of lowering the management cost of the temporary network management. This will lead to a further refinements of the acquisition system.

Overall the UMTS data transmission has been used in most temporary seismic experiments and in all seismic emergencies happened in Italy since 2010 and has proved to be a very cost effective approach with real-time data acquisition rates usually greater than $97 \%$ and all the benefits that result from the fast integration of the temporary data in the National Network monitoring system and in the EIDA data bank.

Acknowledgements. We wish to thank all INGV staff that in the last years have helped setting up, configure and install real-time UMTS seismic stations. We also thank L. Falco, E. D'Alema, W. Thorossian, S. Mazza and A. Rietbrock for valuable discussions and exchange of ideas.

This study was funded by the Italian Presidenza del Consiglio dei Ministri - Dipartimento della Protezione Civile (DPC). This paper does not necessarily represent DPC official opinion and policies.

Edited by: D. Pesaresi

Reviewed by: L. Zimakov and one anonymous referee

\section{References}

AlpArray: available at: http://www.seismo.ethz.ch/alparray/, last access: 4 November 2015.

De Gori, P., Moretti, M., Margheriti, L., Cecere, G., Govoni, A., Criscuoli, F., Mazza, S., Lauciani, V., D’Ambrosio, C., Castagnozzi, A., Memmolo, A., Migliari, F., Minichiello, F., Cardinale, V., Falco, L., Zarrilli, L., De Luca, G., Abruzzese, L., Delladio, A., Scognamiglio, L., and Michelini, A.: Le attività di Pronto Intervento Sismico dell'INGV a seguito del terremoto del 29 dicembre 2013 (area del Matese), Tech. rep., Rapporti Tecnici INGV (ISSN: 2039-7941), available at: http://hdl.handle.net/ 2122/9613 (last access: 4 November 2015), 2014.

Govoni, A., Monachesi, G., Cattaneo, M., Moretti, M., Delladio, A., and Frapiccini, M.: La sequenza sismica del 2010 nelle province di Macerata e Fermo e la sperimentazione della trasmissione dei dati in tempo reale via UMTS, Tech. rep., available at: http://hdl. handle.net/2122/8058 (last access: 4 November 2015), 2012.

Govoni, A., Cavaliere, A., Chiarabba, C., Criscuoli, F., Giovani, L., Margheriti, L., Moretti, M., Piromallo, C., Pondrelli, S., Salimbeni, S., Solarino, S.: L'esperimento Eastern Alpine Seismic 
Investigation (EASI). Il coinvolgimento dell'Istituto Nazionale di Geofisica e Vulcanologia, Tech. rep., Rapporti Tecnici INGV, ISSN: 2039-7941, in press, 2016.

Margheriti, L., Amato, A., Braun, T., Cecere, G., D’Ambrosio, C., De Gori, P., Delladio, A., Gervasi, A., Govoni, A., Guerra, I., Lucente, F. P., Moretti, M., and Selvaggi, G.: Emergenza nell' area del Pollino: le attività della Rete Sismica Mobile, Tech. rep., available at: http://hdl.handle.net/2122/8540 (last access: 4 November 2015), 2013.

Margheriti, L., Moretti, M., Pasta, M., Chiaraluce, L., Frepoli, A., Piccinini, D., Piccolini, U., Colasanti, G., Criscuoli, F., De Gori, P., Ferretti, G., Franceschi, D., Giandomenico, E., Giovani, L., Govoni, A., Marchetti, A., Mazza, S., Pavan, M., Scafidi, D., Silvestri, M., Spallarossa, D., Pintore, S., Lauciani, V., Fiaschi, A., and Turino, C.: Il terremoto del 21 giugno 2013 in Lunigiana. Le attività del coordinamento Sismiko, Tech. rep., available at: http://hdl.handle.net/2122/8899 (last access: 4 November 2015), 2014.

Moretti, M., Antonioli, A., Braun, T., Cattaneo, M., Chiaraluce, L., Fiaschi, A., Govoni, A., Lauciani, V., Marcocci, C., Margheriti, L., Matassoni, L., Mazza, S., Mele, F., Morelli, M., Moschillo, R., Piccinini, D., Pignone, M., Pintore, S., Quintiliani, M., and Saccorotti, G.: La sequenza sismica nel Montefeltro (Forlì - Cesena): l'intervento della Rete Sismica Mobile, Tech. rep., Rapporti Tecnici INGV (ISSN 2039-7941), available at: http://hdl. handle.net/2122/7186 (last access: 4 November 2015), 2011a.
Moretti, M., Chiarabba, C., Cianchini, G., Colasanti, G., Criscuoli, F., De Gori, P., Frepoli, A., Govoni, A., Marchetti, A., and Serratore, A.: Emergenza sismica nel Frusinate (Ottobre 2009Gennaio 2010): l'intervento della Rete Sismica Mobile standalone e l'analisi dati, Tech. rep., available at: http://hdl.handle. net/2122/7185 (last access: 4 November 2015), 2011 b.

Moretti, M., Margheriti, L., and Govoni, A.: Rapid Response to the Earthquake Emergencies in Italy: Temporary Seismic Networks Coordinated Deployments in the Last Five Years, in: Earthquakes and Their Impact on Society, edited by D'Amico, S., Springer Natural Hazards, 585-599, Springer International Publishing, doi:10.1007/978-3-319-21753-6_24, 2016.

Plomerova, J., Bianchi, I., Hetényi, G., Munzarova, H., Bokelmann, G., Kissling, E., AlpArray-EASI Working Group, and AlpArray-EASI Field Team: The Eastern Alpine Seismic Investigation (EASI) project, in: EGU General Assembly Conference Abstracts, vol. 17 of EGU General Assembly Conference Abstracts, 5560, available at: http://meetingorganizer.copernicus. org/EGU2015/EGU2015-5560.pdf, last access: 4 November 2015. 